\title{
Trends in One-Year Recurrent Ischemic Stroke among the Elderly in the USA: 1994-2002
}

\author{
Norrina B. Allen ${ }^{a, d}$ Theodore R. Holford ${ }^{b}$ Michael B. Bracken ${ }^{c}$ \\ Larry B. Goldstein ${ }^{\mathrm{e}}$ George Howard ${ }^{\mathrm{f}}$ Yun Wang ${ }^{\mathrm{a}}$ Judith H. Lichtman ${ }^{a}$ \\ Divisions of a Chronic Disease Epidemiology, ${ }^{b}$ Biostatistics and ${ }^{\mathrm{C} C e n t e r ~ f o r ~ P e r i n a t a l, ~ P e d i a t r i c ~ a n d ~ E n v i r o n m e n t a l ~}$ \\ Epidemiology, Department of Epidemiology and Public Health, Yale University School of Medicine, \\ New Haven, Conn., d Department of Preventive Medicine, Feinberg School of Medicine, Northwestern University,

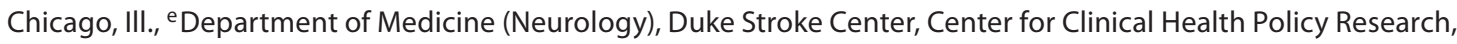 \\ Duke University and Durham VAMC, Durham, N.C., and fDepartment of Biostatistics, School of Public Health, \\ University of Alabama at Birmingham, Birmingham, Ala., USA
}

\section{Key Words}

Acute ischemic stroke - Geographic pattern - Time trends • Recurrent stroke

\begin{abstract}
Background and Purpose: Of the 795,000 strokes occurring in the USA each year, over $20 \%$ are recurrent events. Little is known about how the rates of recurrent stroke in the country have changed over time. Our objective was to determine national trends in 1-year recurrent ischemic stroke rates by US county among the elderly from 1994 to 2002. Methods: Oneyear recurrent stroke rates following incident ischemic stroke (ICD-9 433, 434, 436) among all fee-for-service Medicare beneficiaries were determined by US county for 1994-1996, 1997-1999, and 2000-2002. Bayesian spatiotemporal Poisson modeling was used to determine county-specific trends in recurrent stroke rates over time with risk adjustment for demographics, medical history and comorbid conditions. Results: The analysis included more than 2.5 million beneficiaries (56\% women; mean age: 78 years; $87 \%$ white; $\mathrm{n}=957,933$ for $1994-1996 ; \mathrm{n}=838,330$ for $1996-1999 ; \mathrm{n}=$ 895,916 for 2000-2002) aggregated to all 3,118 US counties. After adjustment for changing patient demographics and
\end{abstract}

comorbidities, there was a $4.5 \%$ decrease in recurrent stroke rates from 1994-1996 (13.2\%) to 2000-2002 (12.6\%; p for trend $<0.0001)$. The geographic and temporal patterns were not uniform; the recurrent stroke rates decreased within sections of the Southeast (the 'stroke belt'), but increased in counties in the middle and western sections of the USA. Conclusions: The overall recurrent ischemic stroke rates declined by almost 5\% from 1994 to 2002, but temporal patterns varied markedly by region. Additional research is needed to identify the reasons for this geographic disparity.

Copyright $\odot 2010$ S. Karger AG, Basel

\section{Introduction}

Stroke-related mortality has declined in the USA over the past few decades [1]. Whether there has been a concomitant decline in the rate of recurrent stroke has not been determined, in part because the USA lack a national stroke surveillance system. Clinical guidelines recom-

The Centers for Medicare and Medicaid Services reviewed and approved the use of their data for this work, and approved submission of the manuscript; this approval is based on data use only.

\section{KARGER \\ Fax +41 613061234 E-Mail karger@karger.ch}

() 2010 S. Karger AG, Basel www.karger.com www.karger.com/ced
Judith Lichtman

Yale University School of Medicine

PO Box 208034

New Haven, CT 06520-8034 (USA)

Tel. +1 203785 3025, Fax +1 203785 6980,E-Mail Judith.Lichtman@yale.edu 
mending the use of evidence-based acute and secondary prevention interventions were published during this period $[2,3]$. Although they remain underutilized [4], the use of secondary prevention treatments such as warfarin for patients with atrial fibrillation and antithrombotic medications at hospital discharge increased among elderly Medicare stroke patients between 1998 and 2001 [5, 6]. The primary objective of this study was to examine trends in ischemic stroke recurrence within 1 year of an initial stroke in a US national sample of elderly Medicare beneficiaries between 1994 and 2002. Because there is geographic variation in the use of secondary preventive care [6], a secondary aim was to determine whether there were regional differences in 1-year recurrent stroke rates over this period.

\section{Methods}

All fee-for-service Medicare beneficiaries aged $\geq 65$ years discharged with an incident ischemic stroke (primary diagnosis: ICD-9-CM 433, 434 and 436) from January 1, 1994, to December 31,1996 , January 1, 1997, to December 31, 1999, and January 1, 2000, to December 31, 2002, were identified from Medicare Provider Analysis and Review files of the Centers for Medicare and Medicaid Services. Incident stroke patients were defined as those who had not had an ischemic stroke hospitalization within the year prior to their index admission. The records were cross-linked with the Medicare Enrollment Database (denominator file) and the patients grouped by their county of residence.

Beneficiaries were excluded if they transferred between acute care facilities, were discharged from a nonacute care hospital, were discharged within 1 day (as it is unlikely that these patients suffered a stroke), were discharged against medical advice, died during the index stroke hospitalization, had crossovers in coverage between fee-for-service and health maintenance organization status or had $<12$ months of continuous Medicare fee-for-service enrollment. Patients were excluded if their county of residence was unknown, if they lived outside the USA or if had missing follow-up information.

Age, sex, race/ethnicity and ZIP code of residence were obtained from the Medicare Enrollment Database. Prior diagnoses including acute myocardial infarction (AMI; ICD-9: 410), cancer (ICD-9: 140-172.9, 174-195.8) and congestive heart failure (ICD9: 428-428.9) as well as comorbidities [diabetes (ICD-9: 250250.3, 250.7), hypertension (ICD-9: 401), dementia (ICD-9: 290290.9), chronic obstructive pulmonary disease (ICD-9: 490-496), obesity (ICD-9: 278.00) and current smoker (ICD-9: 305.1)] and the Deyo comorbidity index [7] were determined using ICD-9CM diagnostic codes from both the index stroke admission and hospitalizations during the prior 12 months. The number of hospitalizations in the year prior to the index stroke was dichotomized as $<2$ versus $\geq 2$.

Recurrent ischemic stroke hospitalizations were identified by primary diagnosis ICD- 9 codes 433, 434 and 436 for 12 months following the index stroke admission. Although there is no stan-
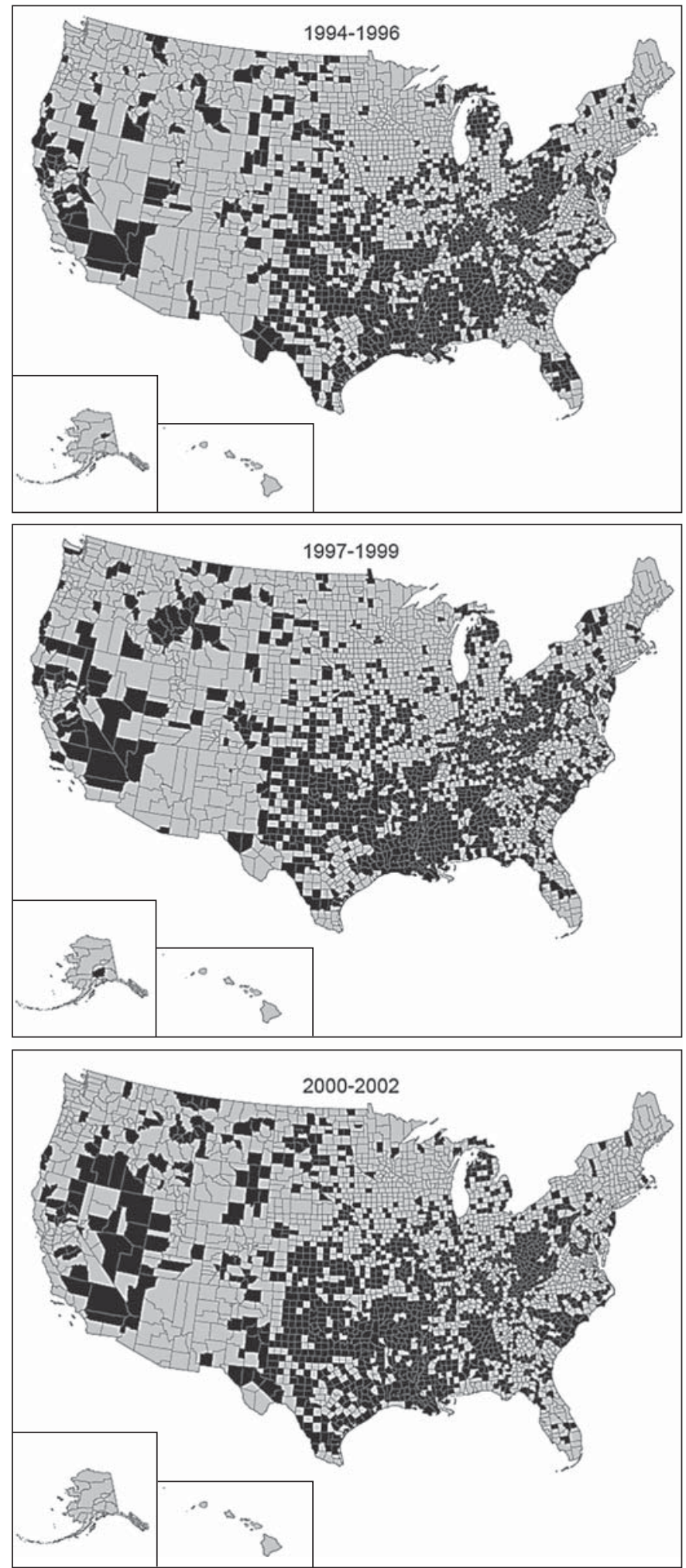

Fig. 1. Counties with 1-year recurrent stroke rates above the national mean from 1994 to 2002 (shown in black); 23 counties were excluded due to percentage errors of $>20 \%$ for risk-standardized rates at any of the time periods.
Allen/Holford/Bracken/Goldstein/ Howard/Wang/Lichtman 
Fig. 2. Percentage change in risk-standardized 1-year recurrent stroke rates by US county from 1994-1996 to 2000-2002; 23 counties were excluded due to percentage errors of $>20 \%$ for risk-standardized rates at any of the time periods.

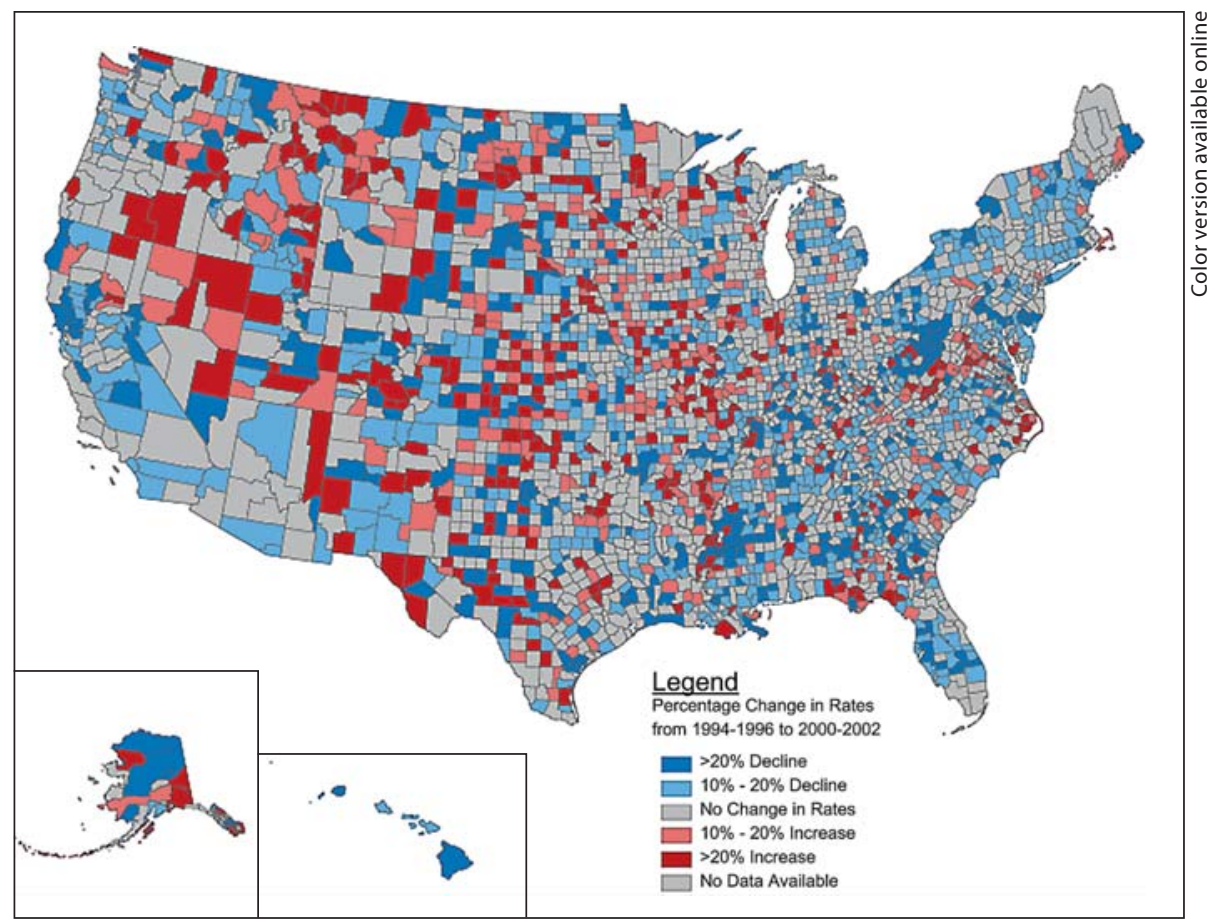

dard definition of a recurrent ischemic stroke [8], prior cohort studies have excluded events within the first 24 h to 28 days [810]. For this analysis, ischemic stroke hospitalizations occurring within 7 days after the discharge date were classified as complications of the incident stroke and were not considered a recurrent event. The Death Master File was used to determine patients' survival or date of death as it contains $95 \%$ of all deaths among individuals aged 65 years and older [11].

The patient's county of residence was identified using the Federal Information Processing Standards (FIPS) code. The ZIP codes were mapped to the county by the Federal Information Processing Standard code that had the greatest proportion of the ZIP code's population, using data from the census. We estimated that $96.2 \%$ of all patients would be assigned the correct county by summing the proportion of each ZIP code's population in the primary county, similar to the methods used in other studies [12].

Recurrent ischemic stroke rates were calculated as the number of patients with a recurrent ischemic stroke per county divided by the number of patient days at risk for each time period. The percent change in risk-standardized 1-year recurrent stroke rates for each county was calculated as the difference between the rate for 1994-1996 and 2000-2002. Patient characteristics were compared across cohorts using $\chi^{2}$ and tests as appropriate. Countyspecific recurrence rates and changes in recurrence rates were mapped to provide a detailed picture of recurrent stroke trends (fig. 1, 2). In order to quantify regional differences, counties were grouped into 9 regions based on US Census Divisions (online suppl. fig. 1, www.karger.com/doi/10.1159/000319028) [13]. The mean risk-standardized recurrent stroke rates and the proportion of counties above the national average were compared by region over time.

Trends in Recurrent Ischemic Stroke Rates
A spatiotemporal bayesian Poisson conditionally autoregressive model [14] was used to determine the risk-standardized rates of stroke recurrence for each county. The conditionally autoregressive model smoothed county risk estimates toward the mean risk of the adjacent counties to provide more precise and reliable estimates, especially for counties with small sample sizes [15]. In addition, this model smoothed rates for each county across adjacent time periods, assuming that changes in rates across counties and over time occur without sudden great variations (i.e. great variations were considered sampling errors and were not included in the final figures). Patient characteristics were included as fixed effects and standardized as the difference from the national mean, providing risk-standardized 1-year recurrent stroke rates for each county. These rates were adjusted for county differences in patient demographics including age, medical history and the prevalence of comorbid conditions.

Model parameters were estimated using Markov chain Monte Carlo simulation, a sampling algorithm used to estimate model parameters in bayesian analyses commonly used for small-area analyses in which rates are determined for relatively small, less populated geographic areas [16]. An uncorrelated (heterogeneity) random effect was incorporated into the model to control for any extra-Poisson variation due to omitted variables, and the deviance information criterion [17] was used to determine model goodness of fit.

The models were run on 3 parallel Gibbs sampler chains and monitored using sample autocorrelations within the chains, plots of sample traces and plots of the Gelman-Rubin reduction factor [18]. Each chain was run for 50,000 iterations, with the first 20,000 iterations being discarded as preconvergence burn-in, and every 10th iteration was retained to reduce autocorrelation. 
Table 1. Characteristics ${ }^{1}$ by cohort: $1994-1996,1997-1999$ and 2000-2002

\begin{tabular}{|c|c|c|c|c|}
\hline & $1994-1996$ & 1997-1999 & $2000-2002$ & $\mathrm{p}$ \\
\hline Female, \% & 55.1 & 55.0 & 55.4 & 0.206 \\
\hline Age, years & $78.3 \pm 1.5$ & $78.4 \pm 1.8$ & $78.1 \pm 1.5$ & $<0.001$ \\
\hline \multicolumn{5}{|l|}{ Race, $\%$} \\
\hline White & 90.0 & 90.2 & 89.9 & 0.680 \\
\hline Black & 7.2 & 6.9 & 7.1 & 0.632 \\
\hline Hispanic & 0.3 & 0.8 & 0.9 & $<0.001$ \\
\hline Other & 2.5 & 2.1 & 2.1 & 0.023 \\
\hline $2+$ prior hospitalizations, $\%$ & 14.3 & 14.6 & 14.5 & 0.183 \\
\hline \multicolumn{5}{|c|}{ Medical history and comorbidities, \% } \\
\hline Deyo score $3+$ & 25.5 & 25.2 & 25.1 & 0.170 \\
\hline Diabetes & 25.1 & 26.4 & 27.7 & $<0.001$ \\
\hline Hypertension & 51.4 & 56.1 & 62.1 & $<0.001$ \\
\hline Current smoker & 3.9 & 6.7 & 9.4 & $<0.001$ \\
\hline Obesity & 0.7 & 1.7 & 1.8 & $<0.001$ \\
\hline Congestive heart failure & 10.1 & 10.7 & 10.5 & $<0.001$ \\
\hline COPD & 17.6 & 18.5 & 19.4 & $<0.001$ \\
\hline AMI & 8.0 & 9.1 & 9.7 & $<0.001$ \\
\hline Cancer & 2.4 & 2.4 & 2.5 & 0.541 \\
\hline Dementia & 7.4 & 7.3 & 6.8 & $<0.001$ \\
\hline
\end{tabular}

Age is expressed as mean $\pm \mathrm{SD}$. COPD $=$ Chronic obstructive pulmonary disease.

${ }^{1}$ Characteristics represent the national average and were determined at the time of incident stroke hospitalization.

Relative risk estimates and 95\% credibility intervals were determined for all covariates. All bayesian modeling was performed with the 64-bit version of WinBUGS 1.4.3 [19]. The risk-standardized 1-year recurrent ischemic stroke rates were mapped by county and classified by quintile. All maps were created using ArcGIS 9.2 by Esri.

\section{Results}

The analyses were based on data from Medicare beneficiaries discharged for an incident stroke in 1994-1996 ( $\mathrm{n}=957,933), 1997-1999(\mathrm{n}=838,330)$ and 2000-2002 ( $\mathrm{n}=895,916)$ who were residents of 3,118 US counties (table 1). The percentage of women with recurrent ischemic stroke and average age remained stable over the 3 time periods. Although they remain a small portion of the population, the percentage of Hispanic stroke patients tripled from $0.3 \%$ in $1994-1996$ to $0.9 \%$ in $2000-2002$. There were only slight changes over time in the percentage of patients hospitalized $\geq 2$ times in the prior year as well as in the percentage of patients with a Deyo score of $\geq 3$. The frequency of individual comorbid conditions such as diabetes, hypertension, smoking, obesity and a history of AMI, however, increased from 1994-1996 through 2000-2002.

The national mean, county-specific, risk-standardized, 1-year recurrent ischemic stroke rate decreased from 13.2 events per 100 person-years (95\% CI: 13.0-13.4) in 1994-1996 over 12.9 (95\% CI: $12.8-13.0$ ) in 1997-1999 to 12.6 (95\% CI: $12.4-12.7$ ) in $2000-2002$ (p for trend $<0.0001)$. The findings were similar for the median county-specific rates $(12.75,12.32$ and 12.22 , respectively). Between 1994-1996 and 2000-2002, US counties had a 4.5\% relative decrease in 1-year recurrent ischemic stroke rates $(\mathrm{p}<0.0001)$. There was a $2.3 \%$ relative decrease between $1994-1996$ and $1997-1999(\mathrm{p}=0.0055)$, and a $2.3 \%$ relative decrease between 1997-1999 and 2000-2002 ( $p=0.0016)$.

Over time, the counties with the highest recurrent stroke rates became more scattered in the Southeast and grew in the Midwest and West (online suppl. fig. 2). Figure 1 shows the increasing heterogeneity of the risk-standardized 1-year recurrent ischemic stroke rates as compared to the national average by county for each of the 3 time periods. Counties with rates above the national mean began to emerge and expand in areas of the West including California, Nevada and Oregon. The geographic variation in the percentage change in recurrent 
Table 2. Risk-standardized recurrent ischemic stroke rates by region

\begin{tabular}{|c|c|c|c|c|c|c|c|c|c|c|c|}
\hline & \multirow{2}{*}{$\begin{array}{l}\text { Number } \\
\text { of } \\
\text { counties }\end{array}$} & \multicolumn{4}{|c|}{ Risk-standardized rates (per 100 person-years) } & \multicolumn{2}{|c|}{ Comparing 1994 to 2000} & \multicolumn{4}{|c|}{ Counties above the national average } \\
\hline & & $\begin{array}{l}1994- \\
1996\end{array}$ & $\begin{array}{l}1997- \\
1999\end{array}$ & $\begin{array}{l}2000- \\
2002\end{array}$ & $\begin{array}{l}\mathrm{p} \\
\text { trend }\end{array}$ & Change, \% & $\mathrm{p}$ & $\begin{array}{l}1994- \\
1996, \%\end{array}$ & $\begin{array}{l}1997- \\
1999, \%\end{array}$ & $\begin{array}{l}2000- \\
2002, \%\end{array}$ & $\begin{array}{l}\mathrm{p} \\
\text { trend }\end{array}$ \\
\hline Entire USA & 3,188 & 13.2 & 12.9 & 12.6 & $<0.001$ & -4.5 & $<0.001$ & 43.0 & 41.5 & 42.3 & 0.713 \\
\hline \multicolumn{12}{|l|}{ Northeast } \\
\hline New England & 67 & 11.4 & 10.8 & 10.5 & $<0.001$ & -7.8 & $<0.001$ & 9.0 & 4.5 & 3.0 & 0.129 \\
\hline Middle Atlantic & 150 & 12.8 & 12.4 & 11.6 & $<0.001$ & -9.2 & $<0.001$ & 34.7 & 37.3 & 24.0 & 0.048 \\
\hline \multicolumn{12}{|l|}{ Midwest } \\
\hline East North Central & 437 & 12.7 & 12.3 & 12.2 & $<0.001$ & -4.5 & $<0.001$ & 40.3 & 33.4 & 35.5 & 0.140 \\
\hline West North Central & 615 & 12.3 & 12.0 & 12.2 & 0.225 & -0.6 & 0.711 & 28.6 & 28.3 & 37.2 & 0.001 \\
\hline \multicolumn{12}{|l|}{ South } \\
\hline South Atlantic & 582 & 13.4 & 13.0 & 12.5 & $<0.001$ & -6.7 & $<0.001$ & 45.2 & 43.0 & 39.9 & 0.066 \\
\hline East South Central & 364 & 14.7 & 14.6 & 13.5 & $<0.001$ & -8.1 & $<0.001$ & 72.3 & 69.0 & 60.2 & $<0.001$ \\
\hline West South Central & 466 & 14.7 & 14.6 & 14.4 & 0.580 & -2.4 & 0.324 & 66.7 & 67.2 & 72.1 & 0.078 \\
\hline \multicolumn{12}{|l|}{ West } \\
\hline Mountain & 276 & 12.5 & 12.1 & 11.7 & 0.520 & -7.0 & 0.253 & 20.3 & 23.9 & 29.0 & 0.017 \\
\hline Pacific & 161 & 11.7 & 11.2 & 11.0 & 0.175 & -5.5 & 0.070 & 23.0 & 22.4 & 19.3 & 0.416 \\
\hline
\end{tabular}

stroke rates remained significant after adjustment for individual patient characteristics. In general, the southeastern USA had a decrease in recurrent ischemic stroke rates, with many of the counties having the highest baseline rates (online suppl. fig. 2) having the largest declines (fig. 2, counties in blue). Despite the national decline in recurrent ischemic stroke rates, some areas of the country had an increase in risk-standardized recurrent ischemic stroke rates over the 3 time periods (i.e. parts of Nevada, southeast Oregon, Montana and other areas in the West and Midwest).

Similar geographic patterns emerged by census division (table 2). The Northeast, East North Central, South Atlantic and East South Central regions experienced decreasing risk-standardized recurrent ischemic stroke rates from 1994 through 2002, with relative declines ranging from 9.2 to $4.5 \%$. The greatest declines were in the Middle Atlantic $(-9.18 \%$; $<<0.0001)$ and East South Central $(-8.09 \%$; $\mathrm{p}<0.0001)$ divisions. These 2 regions also had a decrease in the number of counties above the national average between 1994-1996 and 2000-2002. In contrast, the western half of the USA including the West North Central, West South Central, Mountain and Pacific divisions experienced no statistical improvements in recurrent stroke rates. In fact, the West North Central and Mountain divisions had worsening stroke outcomes with an increasing number of counties with rates above the national average.

Trends in Recurrent Ischemic Stroke Rates

\section{Discussion}

After adjustment for patient characteristics, the 1-year ischemic stroke recurrence rates decreased by almost $5 \%$ among elderly US Medicare beneficiaries between 19941996 and 2000-2002. Despite these overall national declines, the change in recurrence rates was geographically heterogeneous. Many counties in the Midwest and western USA had an increase in recurrent stroke rates, leading to an increase in the number of counties above the national average in the West North Central and Mountain divisions. Counties in the Southeast (i.e. the 'stroke belt') had declines in recurrent stroke, although a high proportion of counties had rates that remained above the national average. Although the reasons for the overall decline and regional differences are unclear, they are not explained by changes in patient demographics or comorbidities as recorded in administrative Medicare data.

Our findings of 1-year recurrent ischemic stroke rates of $13.2-12.6 \%$ per year are consistent with prior regional estimates of 5-15\% [4, 20-25]. Although there are no other national studies of recurrent stroke in the USA, studies from other countries have also found declining rates. For example, the Perth Community Stroke Study in Australia reported a nonsignificant decrease in the 1-year cumulative risk for a recurrent stroke from $16.2 \%$ in $1989-1990$ to $9.0 \%$ in 1995-1996 [12]. Significant reductions in stroke recurrence occurred between 1985 and 2003 in a larger cohort, the Northern Sweden MONICA stroke registry

Cerebrovasc Dis 2010;30:525-532 
[26]. Nondiabetic men and women had 1.7 and $2.7 \%$ yearly declines in recurrent stroke rates from 1985 to 2003 [26].

We found that differences over time in recurrent stroke rates varied by US region. Over the 3 time periods, areas with the highest recurrent stroke rates have migrated from the southeastern USA to the Midwest and Northwest. Although counties in the Southeast had major declines in stroke recurrence, their rates generally remained above the national average. Many counties in the West and Northwest had increasing stroke recurrence rates, leading to an increasing number of counties in these areas with rates above the national average. Studies of the spatiotemporal patterns in stroke mortality have had similar findings [27-29], suggesting that similar underlying mechanisms may be responsible for the observed changes.

An increased use of secondary stroke prevention treatments over the past decade may at least partly explain the decreased rates of recurrent stroke identified in this study. For example, from 1998 to 2001, the use of warfarin and antithrombotic medications at hospital discharge improved among elderly Medicare patients [6]. More recently, the Get With The Guidelines ${ }^{\circledR}$ - Stroke program identified improvements in secondary prevention therapies at discharge from 2003 to 2007 [30]. Unfortunately, little is known about how risk factor control may have changed among stroke patients during the years of our study. However, hypertension, hypercholesterolemia and diabetes treatment and control improved throughout the late 1990s and early 2000s among the general population [31-33], possibly also contributing to reductions in stroke recurrence rates.

Regional differences over the last decade in stroke education, public knowledge of stroke risk factors, diagnosis, evaluation, acute stroke care and secondary prevention efforts could have contributed to the geographic variation in trends observed in this study. For example, some patients previously classified as having a transient ischemic attack might now be diagnosed with a stroke based on neuroimaging (e.g. diffusion-weighted MRI) findings [34]. Little is known about whether criteria for stroke diagnosis vary across the country, specifically whether there are regional differences in the use of diffusion-weighted MRI to distinguish stroke from transient ischemic attack; however, this study antedated the publication of the American Heart Association Scientific Statement addressing the issue [34]. Prior research has shown regional differences in secondary prevention treatments at discharge among Medicare patients $[6,35]$.
However, because this study utilized administrative data, information on the use of secondary preventive interventions was not available. Future research is needed to determine whether the decrease in recurrent stroke rates and the geographic variation in trends observed in this study are due to changes in the use of established secondary prevention measures.

There are several limitations to this study. The reported trends represent those for elderly stroke patients and may not be generalizable to patients under 65 years of age. Stroke, however, is more commonly a disease of the elderly; $75 \%$ of all stroke patients are 65 years and older [1]. We did not include health maintenance organization patients in our sample. Because $<20 \%$ of patients over the age of 65 years receive care via health maintenance organizations, this study provides a national perspective for the majority of elderly fee-for-service Medicare beneficiaries. Stroke patients and their comorbidities were defined by ICD-9 codes at discharge. Detailed clinical information including the results of neuroimaging studies is not included in Medicare administrative data. The selected ischemic stroke codes (ICD-9 433, 434 and 436), however, have been validated in numerous studies [36-38] and have a high sensitivity of $92 \%$ for the identification of patients admitted to the hospital with a stroke [39]. The determination of prior events such as AMI has a high sensitivity and specificity [40], but the determination of behavioral risk factors such as smoking and obesity is less robust [41] and may be underreported in these data. There could be temporal or geographic differences in coding patterns; however, there is no reason to suspect these differences. Because these data predate the implementation of Medicare part D (a federal program for Medicare beneficiaries to subsidize the costs of prescription drugs that began in 2006), we were unable to determine whether potential changes in medication access associated with reductions in cost-related barriers might affect recurrent stroke rates. Regional differences may exist in the risk of stroke in persons under the age of 65 years; however, comparable county-level national data are not available for this younger age group. It is possible that random misclassification, especially of extreme values, may have led to regression to the mean when the rates were repeated over time. Patterns, however, remained consistent when counties with rates with a high percentage error had been excluded. Our findings are reflective of hospitalized ischemic stroke patients. These data do not account for patients with recurrent stroke who were not hospitalized. Although it is estimated that $10 \%$ of all ischemic stroke patients are not hospitalized [42], little is known about whether these rates differ 
for those with a first as compared to a recurrent stroke. Incident stroke patients were defined as those without a stroke hospitalization in the prior year. Therefore, our cohort may not necessarily represent incident strokes only; however, there is no evidence that misclassification varied by geographic region. Because of the small sample size at the county level, we aggregated 3-year periods to form each cohort. It was assumed that recurrence rates remained relatively stable within each 3 -year period; our findings demonstrate that there were only small changes in recurrent stroke rates each year, which supports the validity of this assumption.

Although recurrent stroke rates decreased by almost 5\% in the USA as a whole from 1994 to 2002, the rates increased among counties in the Midwest and Mountain regions of the country. Additional research is needed to explore the reasons for this geographic disparity. If due to systematic differences in the use of secondary preventive interventions, measures to increase adherence could help eliminate these differences.

\section{Acknowledgments}

The project described was supported by grant No. R01NS043322 from the National Institute of Neurological Disorders and Stroke and a dissertation award from the Agency for Healthcare Research and Quality (1R36HS016959-01A1).

\section{Disclosure Statement}

There are no conflicts of interest or disclosures to report.

\section{References}

1 Lloyd-Jones D, Adams R, Carnethon M, de Simone G, Ferguson TB, Flegal K, Ford E, Furie K, Go A, Greenlund K, Haase N, Hailpern S, Ho M, Howard V, Kissela B, Kittner S, Lackland D, Lisabeth L, Marelli A, McDermott M, Meigs J, Mozaffarian D, Nichol G, O’Donnell C, Roger V, Rosamond W, Sacco R, Sorlie P, Stafford R, Steinberger J, Thom T, Wasserthiel-Smoller S, Wong N, WylieRosett J, Hong Y: Heart disease and stroke statistics - 2009 update: a report from the American Heart Association Statistics Committee and Stroke Statistics Subcommittee. Circulation 2009;119:e21-e181.

- 2 Sacco RL, Adams R, Albers G, Alberts MJ, Benavente O, Furie K, Goldstein LB, Gorelick P, Halperin J, Harbaugh R, Johnston SC, Katzan I, Kelly-Hayes M, Kenton EJ, Marks M, Schwamm LH, Tomsick T: Guidelines for prevention of stroke in patients with ischemic stroke or transient ischemic attack: a statement for healthcare professionals from the American Heart Association/American Stroke Association Council on Stroke. Cosponsored by the Council on Cardiovascular Radiology and Intervention. The American Academy of Neurology affirms the value of this guideline. Stroke 2006;37:577-617.

-3 Adams HP Jr, Adams RJ, Brott T, del Zoppo GJ, Furlan A, Goldstein LB, Grubb RL, Higashida R, Kidwell C, Kwiatkowski TG, Marler JR, Hademenos GJ: Guidelines for the early management of patients with ischemic stroke: a scientific statement from the Stroke Council of the American Stroke Association. Stroke 2003;34:1056-1083.
-4 Leoo T, Lindgren A, Petersson J, von Arbin M: Risk factors and treatment at recurrent stroke onset: results from the Recurrent Stroke Quality and Epidemiology (RESQUE) study. Cerebrovasc Dis 2008;25:254-260.

5 Holloway RG, Benesch C, Rush SR: Stroke prevention: narrowing the evidence-practice gap. Neurology 2000;54:1899-1906.

6 Jencks SF, Huff ED, Cuerdon T: Change in the quality of care delivered to Medicare beneficiaries, 1998-1999 to 2000-2001. JAMA 2003;289:305-312.

7 Deyo RA, Cherkin DC, Ciol MA: Adapting a clinical comorbidity index for use with ICD9-CM administrative databases. J Clin Epidemiol 1992;45:613-619.

8 Coull AJ, Rothwell PM: Underestimation of the early risk of recurrent stroke: evidence of the need for a standard definition. Stroke 2004;35:1925-1929.

\9 Sarti C, Stegmayr B, Tolonen H, Mähönen $\mathrm{M}$, Tuomilehto J, Asplund K: Are changes in mortality from stroke caused by changes in stroke event rates or case fatality? Results from the WHO MONICA Project. Stroke 2003;34:1833-1840.

10 Bonita R, Anderson CS, Broad JB, Jamrozik KD, Stewart-Wynne EG, Anderson NE: Stroke incidence and case fatality in Australasia: a comparison of the Auckland and Perth population-based stroke registers. Stroke 1994;25:552-557.

11 Hill ME, Rosenwaike I: The Social Security Administration's Death Master File: the completeness of death reporting at older ages. Soc Secur Bull 2001;64:45-51.
12 Hardie K, Jamrozik K, Hankey GJ, Broadhurst RJ, Anderson C: Trends in five-year survival and risk of recurrent stroke after first-ever stroke in the Perth Community Stroke Study. Cerebrovasc Dis 2005;19:179185.

13 US Census Bureau: Census regions and divisions of the United States, 2009.

14 Besag J, York J, Mollie A: Bayesian image restoration, with two applications in spatial statistics. Ann Inst Stat Math 1991;43:1-59.

15 Carlin BP, Louis TA: Bayes and Empirical Bayes Methods for Data Analysis. Boca Raton, Chapman \& Hall/CRC, 2000.

16 Marshall RJ: A review of methods for the statistical analysis of spatial patterns of disease. J R Stat Soc Ser A 1991;154:421-441.

17 Spiegelhalter D, Best N, Carlin B, van der Linde A: Bayesian measures of model complexity and fit (with discussion). J R Stat Soc Series B Stat Methodol 2002;64:583-640.

18 Gelman A, Rubin DB: Inference from iterative simulation using multiple sequences. Stat Sci 1992;7:457-472.

19 Lunn D, Thomas A, Best N, Spiegelhalter D: WINBUGS - a bayesian modelling framework: concepts, structure, and extensibility. Stat Comput 2000;10:325-337.

20 Petty GW, Brown RD Jr, Whisnant JP, Sicks JD, O'Fallon WM, Wiebers DO: Survival and recurrence after first cerebral infarction: a population-based study in Rochester, Minnesota, 1975 through 1989. Neurology 1998; 50:208-216.

21 Sacco RL, Shi T, Zamanillo MC, Kargman DE: Predictors of mortality and recurrence after hospitalized cerebral infarction in an urban community: the Northern Manhattan Stroke Study. Neurology 1994;44:626-634. 
-22 Eriksson SE, Olsson JE: Survival and recurrent strokes in patients with different subtypes of stroke: a fourteen-year follow-up study. Cerebrovasc Dis 2001;12:171-180.

-23 Lisabeth LD, Smith MA, Brown DL, Moye LA, Risser JM, Morgenstern LB: Ethnic differences in stroke recurrence. Ann Neurol 2006;60:469-475.

24 Matsumoto N, Whisnant JP, Kurland LT, Okazaki H: Natural history of stroke in Rochester, Minnesota, 1955 through 1969: an extension of a previous study, 1945 through 1954. Stroke 1973;4:20-29.

-25 Sacco RL, Wolf PA, Kannel WB, McNamara PM: Survival and recurrence following stroke: the Framingham study. Stroke 1982; 13:290-295.

-26 Rautio A, Eliasson M, Stegmayr B: Favorable trends in the incidence and outcome in stroke in nondiabetic and diabetic subjects: findings from the Northern Sweden MONICA Stroke Registry in 1985 to 2003. Stroke 2008;39:3137-3144.

-27 Casper ML, Wing S, Anda RF, Knowles M, Pollard RA: The shifting stroke belt: changes in the geographic pattern of stroke mortality in the United States, 1962 to 1988. Stroke 1995;26:755-760.

-28 Howard G, Howard VJ, Katholi C, Oli MK, Huston S: Decline in US stroke mortality: an analysis of temporal patterns by sex, race, and geographic region. Stroke 2001;32:22132220 .

-29 Lanska DJ: Geographic distribution of stroke mortality in the United States: 1939-1941 to 1979-1981. Neurology 1993;43:1839-1851.
30 Schwamm LH, Fonarow GC, Reeves MJ, Pan W, Frankel MR, Smith EE, Ellrodt G, Cannon CP, Liang L, Peterson E, Labresh KA: Get With the Guidelines-Stroke is associated with sustained improvement in care for patients hospitalized with acute stroke or transient ischemic attack. Circulation 2009;119: 107-115.

31 Ford ES, Li C, Pearson WS, Zhao G, Mokdad $\mathrm{AH}$ : Trends in hypercholesterolemia, treatment and control among United States adults. Int J Cardiol 2010;140:226-235.

-32 Luepker RV, Arnett DK, Jacobs DR Jr, Duval SJ, Folsom AR, Armstrong C, Blackburn H: Trends in blood pressure, hypertension control, and stroke mortality: the Minnesota Heart Survey. Am J Med 2006;119:42-49.

33 McWilliams JM, Meara E, Zaslavsky AM, Ayanian JZ: Differences in control of cardiovascular disease and diabetes by race, ethnicity, and education: US trends from 1999 to 2006 and effects of Medicare coverage. Ann Intern Med 2009;150:505-515.

34 Easton JD, Saver JL, Albers GW, Alberts MJ, Chaturvedi S, Feldmann E, Hatsukami TS, Higashida RT, Johnston SC, Kidwell CS, Lutsep HL, Miller E, Sacco RL: Definition and evaluation of transient ischemic attack: a scientific statement for healthcare professionals from the American Heart Association/ American Stroke Association Stroke Council, Council on Cardiovascular Surgery and Anesthesia, Council on Cardiovascular Radiology and Intervention, Council on Cardiovascular Nursing and the Interdisciplinary Council on Peripheral Vascular Disease. The American Academy of Neurology affirms the value of this statement as an educational tool for neurologists. Stroke 2009;40: 2276-2293.
35 Jencks SF, Cuerdon T, Burwen DR, Fleming B, Houck PM, Kussmaul AE, Nilasena DS, Ordin DL, Arday DR: Quality of medical care delivered to Medicare beneficiaries: a profile at state and national levels. JAMA 2000;284:1670-1676.

>36 Tirschwell DL, Longstreth WT Jr: Validating administrative data in stroke research. Stroke 2002;33:2465-2470.

>37 Benesch C, Witter DM Jr, Wilder AL, Duncan PW, Samsa GP, Matchar DB: Inaccuracy of the International Classification of Diseases (ICD-9-CM) in identifying the diagnosis of ischemic cerebrovascular disease. Neurology 1997;49:660-664.

-38 Leibson CL, Naessens JM, Brown RD, Whisnant JP: Accuracy of hospital discharge abstracts for identifying stroke. Stroke 1994;25: 2348-2355.

39 Fisher ES, Whaley FS, Krushat WM, Malenka DJ, Fleming C, Baron JA, Hsia DC: The accuracy of Medicare's hospital claims data: progress has been made, but problems remain. Am J Public Health 1992;82:243-248.

40 Kiyota Y, Schneeweiss S, Glynn RJ, Cannuscio CC, Avorn J, Solomon DH: Accuracy of Medicare claims-based diagnosis of acute myocardial infarction: estimating positive predictive value on the basis of review of hospital records. Am Heart J 2004;148:99-104.

$>41$ Quan H, Li B, Saunders LD, Parsons GA, Nilsson CI, Alibhai A, Ghali WA: Assessing validity of ICD-9-CM and ICD-10 administrative data in recording clinical conditions in a unique dually coded database. Health Serv Res 2008;43:1424-1441.

42 Williams GR: Incidence and characteristics of total stroke in the United States. BMC Neurol 2001;1:2. 